УДК 338.27

$10.17213 / 2075-2067-2021-4-195-205$

\title{
ТЕНДЕНЦИИ ВОССТАНОВЛЕНИЯ ЭКОНОМИКИ ПОСЛЕ ПАНДЕМИИ С ПОЗИЦИИ ГУМАНИЗАЦИИ
}

\author{
(C) 2021 г. Н. Н. Чубаева, Е. Г. Попкова
}

\section{Московский государственный институт международных отночений (университет) Министерства иностранных дел РФ (МГИМО МИД РФ), г. Москва, Россия}

Цель исследования. Инициируемые США санкичонные меры в отношении России спровоцировали экономический кризис не только в иелевой стране, но и в остальном мире. Пандемия, которая усугубила нестабильное финансовое положение мирового сообшества, поставила под вопрос иелесообразность дальнейтего противостояния политик. В иелях стабилизации эпидемиологической обстановки объявленный правительствами многих стран локдаун привел к полной или частичной остановке деятельности бизнеса, что прямым образом отразилось на наполняемости бюджетов. И как следствие - невозможность реализаџии социальной политики как основы гуманного экономического развития. Цель статьи заключается в исследований тендениий восстановления экономики после пандемии с позиции гуманизащии.

Методы исследования. Использованы методы статистического и корреляционного анализа, проведена оиенка данных международных организаций, рейтинговых агентств и др.

Результаты исследования. $B$ статье представлены текущие тенденции восстановления экономики в области мер выработки коллективного иммунитета, повымения экономической активности, денежно-кредитной и бюджетно-налоговой политики. На основе корреляциионного анализа оценена объективность выдвинутых предложений по увеличению финансирования программ по борьбе с COVID-19 с иелью повышения экономического роста. По результатам коррелячиии видна нерентабельность выдвинутых предложений, более того, затраченные суммы могут быть перераспределены по другим острым проблемам. Авторами выделены наиболее пострадавшие от кризиса страны и рынки, рекомендованы векторы для адаптации национальных стратегий в целевых сферах. Государство в сложившейся ситуации выступает главным актором восстановления экономики через тщательно спланированные мероприятия с определением исключительных требований каждой сферьл.

Перспективы дальнейших исследований. Акиентировано внимание на новых экологических проблемах, таких как утилизачия индивидуальных средств защиты от вирусов, возросший объем упаковочного материала. При неготовности системы ответственной утилизачии обнуляются достижения многих лет в области противодействия изменению климата.

Ключевые слова: экономический рост; пандемия; новые экологические проблемы; сочиальная поддержка. 


\title{
TRENDS IN ECONOMIC RECOVERY AFTER THE PANDEMIC FROM THE PERSPECTIVE OF HUMANIZATION
}

\author{
(C) 2021 N. N. Chubaeva, E. G. Popkova \\ Moscow State Institute of International Relations (University) \\ of the Ministry of Foreign Affairs of the Russian Federation, Moscow, Russia
}

The purpose of the study. The US-initiated sanctions measures against Russia have provoked an economic crisis not only in the target country, but also in the rest of the world. The pandemic, which has aggravated the unstable financial situation of the world community, has called into question the expediency of further confrontation of policies. In order to stabilize the epidemiological situation, the lockdown announced by the governments of many countries led to a complete or partial shutdown of business activities, which directly affected the filling of budgets. And as a result - the impossibility of implementing social policy as the basis of humane economic development. The purpose of the article is to study the trends of economic recovery after the pandemic from the perspective of humanization.

Research methods. The methods of statistical and correlation analysis were used, the data of international organizations, rating agencies, etc. were evaluated.

The results of the study. The article presents the current trends of economic recovery in the field of measures to develop collective immunity, increase economic activity, monetary and fiscal policy. Based on the correlation analysis, the objectivity of the proposals put forward to increase the funding of programs to combat COVID-19 in order to increase economic growth is evaluated. According to the results of the correlation, the unprofitability of the proposals put forward is visible, moreover, the amounts spent can be redistributed to other acute problems. The authors identified the countries and markets most affected by the crisis, recommended vectors for adapting national strategies in target areas. In the current situation, the state acts as the main actor of economic recovery through carefully planned measures with the definition of the exceptional requirements of each sphere.

Prospects for further research. Attention is focused on new environmental problems, such as the disposal of personal protective equipment against viruses, the increased volume of packaging material. If the responsible recycling system is not ready, the achievements of many years in the field of countering climate change are reset.

Key words: economic growth; pandemic; new environmental problems; social support.

Введение. Значительное количество ученых давно занимаются изучением типов экономического роста. Определение, существующее в научной среде и описывающее экономический рост за счет увеличения масштаба производства, различного вида капиталовложений и рост за счет повышения качества задействованных ресурсов, именуется экстенсивным и интенсивным типом соответственно [3]. Современные тенденции опираются на интенсивный тип экономического развития [2], фокусом которого выступает человеческий капитал как фактор основных моделей экономического роста и фундамент гуманизации. С учетом глобальной тенденции современности исследование качества этой составляющей экономического роста стало основой комплексного исследования, сформировав понятие гуманизации экономического роста.

Таким образом, под гуманизацией экономического роста рассматривается тип развития с учетом потребностей человека, в усло- 
виях которых развиваются его интеллектуальные и физические данные как производные экономического роста [1].

Принимая во внимание негативное влияние пандемии в 2020-2021 годах на экономику, можно сказать, что возникшие проблемы поставили под угрозу дальнейшее глобальное развитие. Вынужденный перевод работы в дистанционный формат вызвал частичное или полное закрытие предприятий, что стало результатом снижения мирового ВВП, роста безработицы, и самое важное для мирового сообщества - обнуление всех достижений за последние десятилетие. Для выравнивания сложившейся ситуации необходим пересмотр действующих национальных стратегий в кратчайшие сроки, а взаимодействие стран ускорит достижение ключевых показателей экономики и повысит их эффективность.

\section{Методы (теоретические основы).} В рамках данной статьи проведены исследования существования зависимости средств, затраченных на меры борьбы с коронавирусной инфекцией и восстановление экономики. В странах с оптимальным сочетанием данных проведен анализ тенденций национальных стратегий и проводимой политики, направленной на решение сопутствующих проблем пандемии. Основное внимание уделено безработице как основному препятствию восстановления экономики путем создания условий поддержки бизнеса, деятельность которого влияет на уровень благосостояния общества. Проведена оценка искомых показателей в развитых странах, предложены рекомендации для внедрения в России.

Методом статистического и корреляционного анализа проведена оценка данных международных организаций, рейтинговых агентств, таких как Международный валютный фонд, РwН, ОЭСР и др.

Результаты. Экономический кризис 2018 года, усугубившийся пандемией, затронул все без исключения страны, с разницей лишь в степени распространения негативных последствий на внутренних рынках. Объяснимая актуальность проводимых исследований мировым сообществом определяется доказанным постулатом достижения макси- мальных результатов и их скорости при условии глобального взаимодействия. По данным международного валютного фонда [16], первые показатели восстановления экономики будут в 2022 году, они же будут значительно отличаться от оптимальных темпов развития, колеблющихся в пределах 2-3\% [1], что подтвердит фазу восстановления. По прогнозным расчетам $\mathrm{PwH}$, в физическом измерении экономика к 2042 году возрастет вдвое [17].

Проводя анализ данных Международного валютного фонда, можно сделать вывод, что прослеживаются максимальные просадки в странах с формирующимся рынком и в развивающихся странах с низким доходом (рис. 1), отмечена меньшая уязвимость стран с развитой экономикой.

В расчетах на рисунке 1 используется реальный ВВП на душу населения (по паритету покупательной способности в долларах США на 2017 г.).

Следует обратить внимание, что темпы экономического роста показывают противоположные значения. Снижения темпов роста ВВП оказались в развитых странах более глубокие, чем в развивающихся странах и странах с низким доходом (табл. 1).

Такая противоположность представленных данных объясняется включением в диаграмму социальных показателей: увеличившаяся разница доходов и снизившаяся покупательская способность, глубина провалов рынка капиталов (эксперты Международного валютного фонда отмечают, что это особенно коснулось автомобильного рынка, потребительских и инвестиционных товаров, рынка товаров производственного назначения) [16]. Сюда же включены и индикаторы роста неформального сектора экономики, а также количество пострадавших от COVID-19 по здоровью, лишившихся работы, вынужденных сменить трудовую деятельность и др.

Учитывая постепенный рост вакцинирования, можно подтвердить зависимость между объемом средств, потраченных на вакцинацию населения, и ростом ВВП. Глава ВОЗ Тедрос Гебрейесус заявил о необходимости увеличения затрат на данную программу с 19 млрд. долл. до 35-45 млрд. долл., объединив это в представленных прогнозных данных $\mathrm{PwH}$ и всемирного экономического форума, тогда рост мирового ВВП в 2022 году составит 4,4\%. 
Таблица 1

Темпы экономического роста по группам стран (составлено автором)

\begin{tabular}{|c|c|c|c|c|c|c|}
\hline & & & & \multicolumn{3}{|c|}{ Прогноз } \\
\hline & 2018 & 2019 & 2020 & 2021 & 2022 & 2026 \\
\hline ВВП - Мир & 3,6 & 2,8 & $-3,3$ & 6 & 4,4 & 3,3 \\
\hline ВВП - США & 3 & 2,2 & $-3,5$ & 6,4 & 3,5 & 1,3 \\
\hline ВВП - СРЭ & 2,3 & 1,6 & $-4,7$ & 5,1 & 3,6 & 1,5 \\
\hline ВВП - СФР & 4,5 & 3,6 & $-2,2$ & 6,7 & 5 & 4,4 \\
\hline ВВП - РСНД & 2,7 & 2,9 & $-2,2$ & 2 & 3 & 2,2 \\
\hline
\end{tabular}
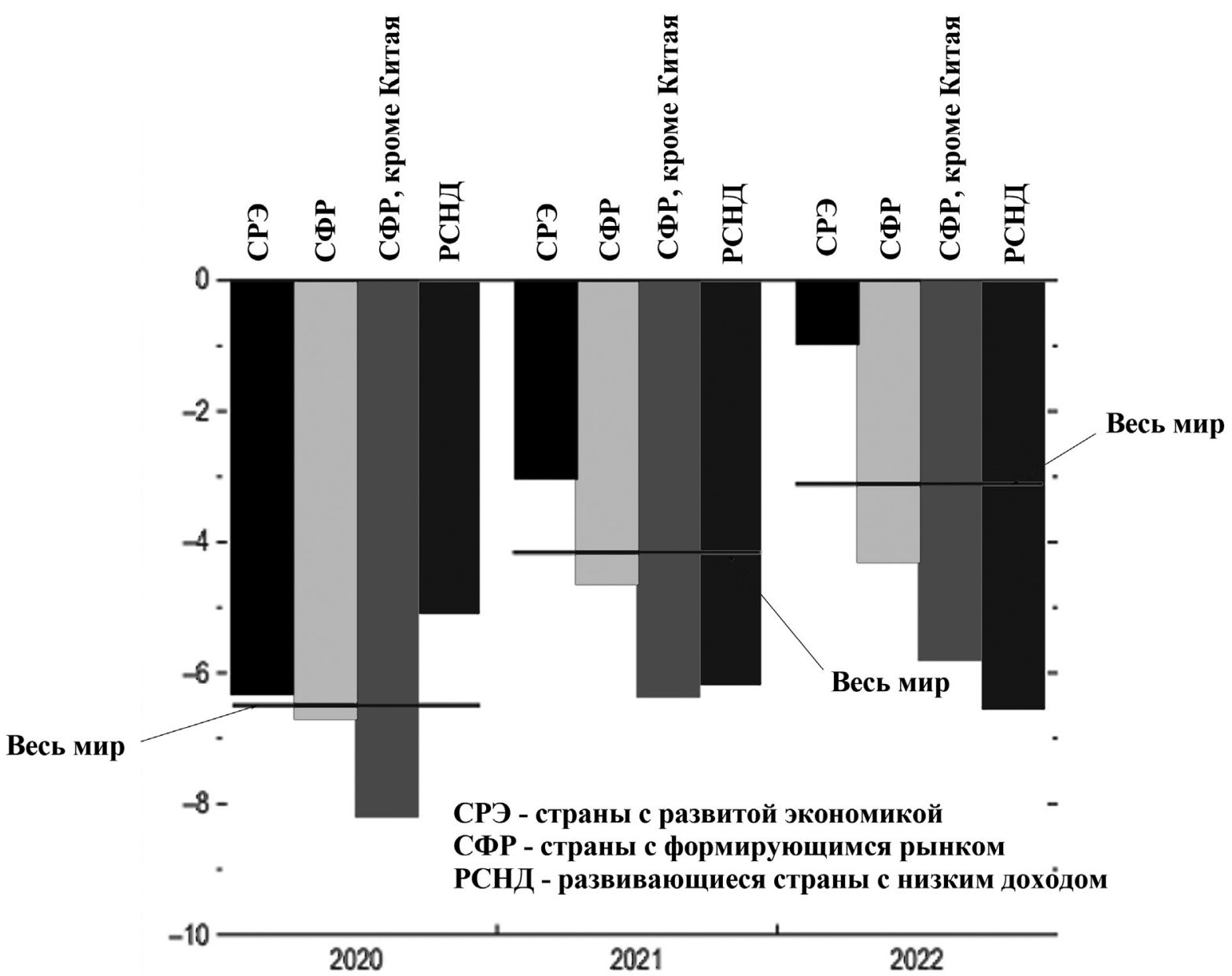

Рис. 1. Группы наиболее пострадавших стран (пересмотр данных по совокупному росту ВВП на душу населения с 2019 г. в прогнозах ПРМЭ за январь 2020 г. и апрель 2021 г., \%) 
Расширяя процент вакцинированных людей против вируса COVID-19, правительства не только создают себе почву для устойчивого экономического роста, но и повышают степень гуманного развития путем увеличения показателей благополучия, таких как обеспечение достаточного количества средств, создание благоприятной среды жизни, обеспечение продовольственной безопасности, создание безопасных рабочих мест и др.
В рамках исследования проведем корреляционный анализ зависимости затрат на стабилизацию эпидемиологической обстановки в стране и скорости восстановления экономики по индикаторам ВВП (табл. 2).

По правилам корреляционного анализа на первое место мы должны определить переменную, в отношении которой проверяется возможность существования исследуемой зависимости.

Зависимость расходов на борьбу с COVID-19 и роста ВBП'

Таблица 2

\begin{tabular}{|l|c|c|c|c|}
\hline \multicolumn{1}{|c|}{ Страна } & $\begin{array}{c}\text { Сумма, выделенная на } \\
\text { борьбу с COVID-19, } \\
\text { млрд долл. США }\end{array}$ & $\begin{array}{c}\text { Население, } \\
\text { млн. чел }\end{array}$ & $\begin{array}{c}\text { Затраты } \\
\text { на человека, } \\
\text { долл. США }\end{array}$ & $\begin{array}{c}\text { ВВП на душу } \\
\text { населения в 2020 г., } \\
\text { в долл. США }\end{array}$ \\
\hline США & 610 & 329,7 & 185 & 66194,4 \\
\hline Канада & 75 & 38 & 197,4 & 47031,8 \\
\hline Германия & 810 & 82 & 987,8 & 44667 \\
\hline Великобритания & 424 & 66,7 & 635,7 & 39932,5 \\
\hline Италия & 28 & 60,2 & 46,5 & 31657,7 \\
\hline Китай & 100 & 1402,7 & 7,1 & 10643,7 \\
\hline Россия & 5 & 146,7 & 3,4 & 11980,7 \\
\hline Япония & 11,5 & 125,9 & 9,1 & 41344,8 \\
\hline ОАЭ & 27,2 & 9,9 & 274,7 & 68250 \\
\hline
\end{tabular}

Таблица 3

\section{Корреляция данных, представленных в таблице 2 (составлено автором)}

\begin{tabular}{|c|c|c|c|c|}
\hline & $\begin{array}{l}\text { ВВП на душу } \\
\text { населения, } \\
\text { долл. США }\end{array}$ & $\begin{array}{c}\text { Сумма, выделенная } \\
\text { на борьбу с COVID-19, } \\
\text { млрд. долл. США }\end{array}$ & $\begin{array}{c}\text { Затраты } \\
\text { на человека, } \\
\text { долл. США }\end{array}$ & $\begin{array}{c}\text { ВВП, } \\
2020 \text { г. }\end{array}$ \\
\hline $\begin{array}{l}\text { ВВП на душу населения, } \\
\text { долл. США }\end{array}$ & 1 & & & \\
\hline $\begin{array}{l}\text { Сумма, выделенная на } \\
\text { борьбу с COVID-19, } \\
\text { млрд. долл. США }\end{array}$ & 0,352 & 1 & & \\
\hline $\begin{array}{l}\text { Затраты на человека, } \\
\text { долл. США }\end{array}$ & 0,318 & 0,803 & 1 & \\
\hline ВВП, 2020 г. & $-0,391230771$ & $-0,083145472$ & $-0,358081596$ & 1 \\
\hline
\end{tabular}

1 Источник: отчет Международного валютного фонда; Перспективы развития экономики, 2021; дата-сет «Большие данные современной мировой экономики: цифровая платформа интеллектуальной аналитики 2020». 
Полученные результаты позволяют сделать два вывода:

1) высокая мультиколлинеарность $(0,802727966)$ говорит о сильной зависимости величины суммы, выделенной на борьбу с вирусом COVID-19, и суммы, рассчитанной на одного человека, является логическим выводом и должна быть исключена из возможной математической модели;

2) зависимость между выделяемой суммой на стабилизацию эпидемиологической ситуации в стране и возможным ростом ВВП (что является акцентом нашего внимания) очень слабая - 0,352353017. Следовательно, можно говорить о прямом влиянии других факторов, стимулирующих восстановление темпов роста экономики.

Составление математической модели по представленным к анализу переменным возможно, но релевантной для использования она не будет [8].

По мнению американского ученого Д. Стиглица, государству отводится главная роль регулятора экономики [6]. Регулирование деятельности налоговой ставкой ускорит восстановление предприятий, жизнеспособных до пандемии, с возвращением уволенных и потерявших работу сотрудников. Для более эффективной реабилитации пострадавших секторов бизнеса помощь компаниям следует делать адресной. МВФ называет такой тип компаний «контактоемким сектором», к нему относятся различного типа магазины, гостиницы, рестораны, транспорт и услуги любого направления, осуществляемые непосредственно при личном контакте. Для адаптации каждой сферы к новым условиям и восстановления экономики требуется организация мер со значительной поддержкой бизнеса государствами и мировыми организациями.

Вынужденные меры глобальной самоизоляции населения привели к закрытию или сокращению объемов деятельности бизнеса, что отразилось на скачке безработицы, а это в свою очередь, сокращает объем располагаемых средств к существованию [19]. В связи с этим категория людей, лишившихся работы, вынуждена искать альтернативные источники дохода либо менять квалификацию. Национальными программами сокращения увеличившегося процента безработных граждан выступает профессиональная переподготов- ка, преимущественным образом связанная с обучением цифровой грамотности. Кроме того, следует уделять достаточно внимания программам повышения профессионального образования ввиду неизбежности перехода всего пространства жизнедеятельности в среду с развитой цифровой основой.

Национальные стратегии стран в области цифровизации образования нацелены на единые принципы и различаются лишь инструментами их достижения, а именно:

- созданием условий, препятствующих распространению вирусов и созданием обстановки, охраняющей здоровье;

- сохранением финансирования сферы образования как источника долгосрочного экономического роста;

- построением системы образования, устойчивой к будущим угрозам, вызванным пандемией.

Оставление без поддержки государством граждан, потерявших работу, сопряжено с рисками как социальными, так и экономическими. Отсутствие стабильного дохода отражается на благосостоянии и расслоении общества, а также различии между богатыми и бедными странами, что препятствует одной из гуманных целей развития экономики [7].

Рассматривая цифровизацию в контексте гуманизации экономики, мы можем говорить о неразделимости принципов. Автоматизация и роботизация деятельности не только повышают темпы восстановления экономики за счет увеличения производительности и качества конечного продукта, но и облегчают труд сотрудников и делают его безопаснее. Также емкость и качество человеческого капитала влияют первостепенным образом на экономический рост.

Расширение политики субсидирования необходимо для обеспечения экономического роста в долгосрочной перспективе, но стоит сказать об обратной стороне поддержки. Дотационная помощь и субсидирование бизнеca, как и поддержка населения, могут привести к ограничениям ввода новых предприятий, перераспределению капитала и трудовых ресурсов, а население перестанет быть заинтересованным в поиске работы, полагаясь на социальные выплаты [5].

Обоснованность предлагаемых для преодоления кризисной ситуации мер должна 
главным образом быть в условиях тесного международного сотрудничества и реализовываться в следующих направлениях:

- организация взаимодействия правительства стран для реализации программ выработки коллективного иммунитета, несмотря на имеющиеся политические разногласия. Правительствам стран для увеличения масштаба вакцинирования следует не ограничивать действия по производству и приграничному перемещению готовых вакцин и готового медицинского оборудования;

- минимизация долговременного ущерба, связанного преимущественным образом c экономической активностью населения в странах с развивающимися и формирующимися рынками;

- предотвращение частоты возникновения стихийных бедствий. По причине нехватки средств в бюджетах ввиду перераспределения средств на борьбу с пандемией усилия по борьбе со стихийными бедствиями были снижены, что влечет за собой серьезные гуманитарные последствия;

- снижение торговых и технологических барьеров. Ограничения, существовавшие еще до COVID-19, влияют на технологические риски, связанные с цифровизацией, автоматизацией, и в целом провоцируют увеличение экономического неравенства;

- смягчение мер денежно-кредитной и налогово-бюджетной политики должно быть синхронизировано между странами, равными по уровню экономического развития. В этом случае эффективность будет максимальна.

Если рассматривать конкретизированно предлагаемые мировыми организациями меры в целях восстановления экономики, то в первую очередь предлагается сосредоточить усилия на сфере здравоохранения [16]. Экономические выгоды в сравнении с расходами на борьбу с пандемией, создание вакцин и последующая вакцинация в логическом представлении несоизмеримы. Но по расчетам, представленным выше, мы показали, что прямой взаимосвязи средств, потраченных на борьбу с COVID-19, и ростом экономики нет, либо она настолько слабая, что достоверность предложенной модели была бы настолько низкая, что противоречила практическим соображениям представлять ее в качестве научного открытия.
Тем не менее, стоит заметить, что незначительная степень влияния вакцинации на экономический рост существует. Второй аспект необходимости вакцинации состоит в потребности любого государства в здоровой нации с позиции восприятия населения как одного из основных факторов, составляющих модель экономического роста.

Следующей тенденцией в мировой экономике выступает трансформация денежнокредитной и бюджетно-налоговой сферах. Принципиально новым является предложение инициировать схожесть мер в странах одинакового типа развития по классификации МВФ [10], ключевым моментом служит единовременная ратификация мер. Целевое назначение таких программ призвано повысить экономическую активность бизнеса и населения, особенно это должно касаться предприятий малого, среднего бизнеса и домашних хозяйств. При этом отчетность по выделенным средствам является обязательным условием и в данном сегменте исполняется не в полной мере, что вызывает ограничения между продуктивным взаимодействием триады «Государство - Бизнес - Общество». Также в этом направлении необходимо продумать меры выхода, отмены субсидирования в будущем таким образом, чтобы реципиенты помощи продолжили работать на достигнутом уровне.

В России Правительством, Центральным банком, Министерством экономического развития была успешно внедрена программа поддержки бизнеса, которая показала значительные результаты по восстановлению экономики:

- на финансирование мер антикризисной политики выделено 3,26 трлн. руб. $(3,05 \%$ от ВВП) [11];

— для 1,6 млн. организаций предоставлена отсрочка по кредитным договорам на сумму 89,6 млрд. руб.;

- 40 тысяч социально-ориентированных НКО освобождены от налоговых обязательств в первом полугодии 2020 года;

- 31,6 млрд. руб. выплачено ИП для покрытия задолженностей по зарплате за 2 месяца;

- 130 млрд. руб. выдано в рамках беспроцентного кредита предприятиям, также для выплат зарплаты сотрудникам;

- отменено около 500 тысяч проверок бизнеса аудиторскими компаниями (исключение составляют проверки, несущие угрозу жизни). 
Прошедший 2020 год ознаменовался улучшением состояния экологии в части сокращения выбросов углекислых газов, что снижает вероятность изменения климата на $4 \%$. Это вызвано в большей степени не сокращением выбросов $\mathrm{CO}_{2}$, а остановкой работы предприятий вследствии объявляемого правительствами режима блокировки свободного перемещения граждан. Чтобы избежать резкого скачка выбросов в будущих периодах, когда будут отменены все эпидемиологические ограничения и производства будут запущены в полном объеме, необходимо сейчас провести модернизацию производств в соответствии с требованиями международных организаций [18].

Поддержкой со стороны государства могут выступать налоговые послабления для компаний, функционирующих по принципам безуглеродной экономики и занимающихся разработкой «зеленых» технологий. С момента ратификации «Парижского соглашения по климату до 2030 года» Россия ведет активную работу в этой области.

Новая экологическая проблема, вставшая перед всем мировым сообществом и спровоцированная мерами борьбы с пандемией, - это утилизация пластика. В десятки раз увеличилась утилизация упаковки товаров всевозможного назначения, использованных медицинских масок, латексных перчаток, переработка которых зачастую осуществляется сжиганием, а это в свою очередь несет выбросы $\mathrm{CO}_{2}$ [13]. Системы утилизации вышеперечисленных товаров оказались попросту не готовы к такому авральному наплыву мусора.

Заключение. По результатам проведенного исследования выделены особо пострадавшие отрасли, обозначены векторы направления политики государств для достижения экономического роста в новых условиях, вызванных пандемией.

Предложенное дополнительное финансирование мер по борьбе с COVID-19, по математическим расчетам, не влияет на рост экономики. Возможно, при включении в расчет временного лага корреляция данных будет наблюдаться в большей степени. Тем не менее, вакцинация с позиции гуманизации жизни и сохранения масштабности рабочей силы как фактора экономического роста необходима.
Переход на дистанционный режим работы и внедрение цифровых технологий выявили профессиональную неготовность персонала, что привело к росту сокращений. Одна из главных задач правительств - оказать поддержку населению, потерявшему работу, организовать помощь в переквалификации с освоением навыков цифровой грамотности.

Для сокращения разрывов экономической активности внутри стран и между ними рекомендуется трансформация налогово-бюджетной и кредитно-денежной систем, а также условий, препятствующих трансграничной торговле. Принципиально новым выступает максимальное единообразие и одномоментность введения изменений в странах одинакового уровня экономического развития.

В части стабилизации экологической обстановки и обеспечения устойчивости изменения климата по каналам социальной рекламы необходимо повышать сознательность граждан и убеждать их внимательнее относиться к вопросу утилизации мусора. Имеющиеся перерабатывающие предприятия следует модернизировать в соответствии с возросшими потребностями.

\section{Литература}

1. Асемоглу Д. Введение в теорию современного экономического роста / Пер. с англ. В 2 книгах. - М.: Издательский дом «Дело» РАНХиГС, 2018. - 930 с.

2. Сафрончук М.В. Экономический рост// Курс экономической теории: учебник. 5-е испр., доп. и перераб. изд. - Киров: АСА, 2004. - C. 605-644.

3. Солоу Р.М. Экономическая теория ресурсов или ресурсы экономической теории// Вехи экономической мысли. Т. 3. Рынки факторов производства / Под общ. ред. В.М. Гальперина. - СПб.: Экономическая школа, 2000.

4. Киселева Е.А. Экономическая теория: учебник / Е.А. Киселева, М.В. Сафрончук // Под ред. Чепурина М.Н. - М.: Деловая литература, 2011. - С. 552.

5. Шпилев Д. А. Социальные гарантии в правовых системах России и Германии. Нижний Новгород, НИСОЦ, 2009. - С. 54.

6. Stiglitz J. New theoretical perspectives on the distribution of income and wealt among 
individuals. Part 4: Land and credit [Electronic resource] // National bureau of economic research. - May 2015. — URL: https://www. nber.org/system/files/working_papers/w21192/ w21192.pdf.

7. Blanchard O., Philippon T. A New Policy Toolkit is Needed as Countries Exit COVID-19 Lockdowns. PIEE Policy Brief 20-8 // Peterson Institute for International Economics. - Washington, DC, 2020. - P. 20.

8. Ebeke C., Jovanovic N. Corporate Liquidity and Solvency in Europe during COVID-19: The Role of Policies. - IMF Working paper, 2021. - P. 48.

9. Бюджет для граждан. К Федеральному закону о федеральном бюджете на 2021 год и на плановый период 2022 и 2023 годов. Министерство финансов Российской Федерации. - М., 2020.

10. Организация экономического сотрудничества и развития [Электронный ресурс]/ Статистика. — Режим доступа: https://stats.oecd.org/.

11. О поддержке малого и среднего предпринимательства в Российской Федерации в условиях изменившейся экономической ситуации, вызванной распространением новой коронавирусной инфекции [Электронный ресурс] / Министерство экономического развития. - Режим доступа: https://www.economy. gov.ru/material/file/9b1c66345f1044d7620f248 3492fbb3b/msp_covid_19.pdf.

12. Бюллетень о текущих тенденциях российской экономики. Экология и экономика: тенденция к декарбонизации [Электронный ресурс] / Аналитический центр при Российской Федерации. - Окябрь 2020. Режим доступа: https://ac.gov.ru/uploads/2Publications/BRE/ \%D0 \%BE\%D0\%BA\%D $1 \% 82 \% \mathrm{D} 1 \% 8 \mathrm{~F} \% \mathrm{D} 0 \% \mathrm{~B} 1 \% \mathrm{D} 1 \% 80 \% \mathrm{D} 1 \% 8$ C_web.pdf.

13. Международная конференция «Преобразование отходов в ресурсы 2021 г.» [Электронный ресурс] / Международная ассоциация по борьбе с твердыми отходами. Режим доступа: http://www.waste-to-resources. $\mathrm{eu} / 2021$ en.html.

14. Сенатор Грем. Закон о защите американской безопасности от агрессии Кремля от 2018 года [Электронный ресурс] // 115-й конгресс. 2-я сессия. Конгресс США. Режим доступа: https:/www.congress.gov/ bill/115th-congress/senate-bill/3336/text?r=12.
15. COVAX. Working for global equitable access to COVID-19 vaccines [Electronic resource] // World Heaith Organization. - URL: https://www. gavi.org/vaccineswork/covid-19-vaccine-race.

16. Managing Divergent Recoveries [Electronic resource] / World economic outlook. International monetary fund. - Apr. 2021. 208p. — URL: https://www.imf.org/en/Publications/WEO/Issues/2021/03/23/world-economicoutlook-april-2021.

17. The long view how will the global economic order change by $2050 / /$ The world in 2050. - PwC, 2017.

18. Zero Routine Flaring by 2030 [Electronic resource] // The World Bank. - May 10, 2017. - URL: http://www.worldbank.org/en/ programs/zero-routine-flaring-by-2030.

19. Кан E.H. Гуманизация экономического роста: сущность, направления, механизм регулирования: автореф. дис. ... канд. экон. наук. - Санкт-Петербург, 2018.

\section{References}

1. Asemoglu D. Vvedenie v teoriju sovremennogo jekonomicheskogo rosta / Per. s angl. V 2 knigah [Introduction to the theory of modern economic growth / Trans. from English. In 2 books]. - Moscow: Izdatel'skij dom «Delo» RANHiGS, 2018. - 930 p.

2. Safronchuk M.V. Jekonomicheskij rost [Economic growth] // Kurs jekonomicheskoj teorii: uchebnik. 5-e ispr., dop. i pererab. izd. [Course of economic theory: textbook. 5th ispr., additional and revised ed.]. - Kirov: ASA, 2004. - Pp. 605-644.

3. Solou P.M. Jekonomicheskaja teorija resursov ili resursy jekonomicheskoj teorii [Economic theory of resources or resources of economic theory] // Vehi jekonomicheskoj mysli. Vol. 3. Rynki faktorov proizvodstva [Milestones of economic thought. Vol. 3. Markets of factors of production] / Pod obshh. red. V.M. Gal'perina [In V.M. Galperin (eds.)]. — Saint Petersburg: Jekonomicheskaja shkola, 2000.

4. Kiseleva E.A. Jekonomicheskaja teorija: uchebnik [Economic theory: textbook]/ E.A. Kiseleva, M.V. Safronchuk // Pod red. Chepurina M.N. In Chepurin M.N. (eds.). Moscow: Delovaja literatura, 2011. — P. 552.

5. Shpilev D.A. Social'nye garantii v pravovyh sistemah Rossii i Germanii [Social guar- 
antees in the legal systems of Russia and Germany]. — Nizhnij Novgorod, NISOC, 2009. P. 54.

6. Stiglitz J. New theoretical perspectives on the distribution of income and wealt among individuals. Part 4: Land and credit [Electronic resource] // National bureau of economic research. - May 2015. — URL: https://www. nber.org/system/files/working_papers/w21192/ w21192.pdf.

7. Blanchard O., Philippon T. A New Policy Toolkit is Needed as Countries Exit COVID-19 Lockdowns. PIEE Policy Brief 20-8 // Peterson Institute for International Economics. - Washington, DC, 2020. - P. 20.

8. Ebeke C., Jovanovic N. Corporate Liquidity and Solvency in Europe during COVID-19: The Role of Policies. - IMF Working paper, 2021. - P. 48.

9. Bjudzhet dlja grazhdan. K Federal'nomu zakonu o federal'nom bjudzhete na 2021 god i na planovyj period 2022 i 2023 godov. Ministerstvo finansov Rossijskoj Federacii [Budget for citizens. To the Federal Law on the Federal Budget for 2021 and for the Planning period of 2022 and 2023. Ministry of Finance of the Russian Federation]. - Moscow, 2020.

10. Organizacija jekonomicheskogo sotrudnichestva i razvitija [Organization for Economic Cooperation and Development] [Jelektronnyj resurs] / Statistika [Statistics]. — URL: https:// stats.oecd.org/.

11. O podderzhke malogo i srednego predprinimatel'stva v Rossijskoj Federacii v uslovijah izmenivshejsja jekonomicheskoj situacii, vyzvannoj rasprostraneniem novoj koronavirusnoj infekcii [On the support of small and medium-sized businesses in the Russian Federation in the conditions of the changed economic situation caused by the spread of a new coronavirus infection] [Jelektronnyj resurs] / Ministerstvo jekonomicheskogo razvitija [Ministry of Economic Development]. — URL: https://www.economy. gov.ru/material/file/9b1c66345f1044d7620f248 3492fbb3b/msp_covid_19.pdf.

12. Bjulleten' o tekushhih tendencijah rossijskoj jekonomiki. Jekologija i jekonomika: tendencija k dekarbonizacii [Bulletin on the current trends of the Russian economy. Ecology and
Economics: the trend towards decarbonization] [Jelektronnyj resurs] / Analiticheskij centr pri Rossijskoj Federacii [Analytical Center under the Russian Federation]. - October 2020. URL: https://ac.gov.ru/uploads/2-Publications/ BRE/ $\%$ D0 \%BE\%D0\%BA\%D1 \%82\%D1\%8 F\%D0 \%B1\%D1\%80\%D1\%8C_web.pdf.

13. Mezhdunarodnaja konferencija «Preobrazovanie othodov v resursy 2021 g.» [International Conference «Transformation of waste into resources in 2021»] [Jelektronnyj resurs] / Mezhdunarodnaja associacija po bor'be s tverdymi othodami [International Association for the Control of Solid Waste]. — URL: http://www. waste-to-resources.eu/2021_en.html.

14. Senator Grem. Zakon o zashhite amerikanskoj bezopasnosti ot agressii Kremlja ot 2018 goda [Senator Grem. The Law on the Protection of American Security from the Kremlin's aggression of 2018] [Jelektronnyj resurs] // 115j kongress. 2-ja sessija. Kongress SshA [115th Congress. 2nd session. US Congress]. - URL: https://www.congress.gov/bill/115th-congress/ senate-bill/3336/text?r=12.

15. COVAX. Working for global equitable access to COVID-19 vaccines [Electronic resource] // World Heaith Organization. - URL: https://www.gavi.org/vaccineswork/covid-19vaccine-race.

16. Managing Divergent Recoveries [Electronic resource] / World economic outlook. International monetary fund. - Apr. 2021. 208 p. - URL: https://www.imf.org/en/Publications/WEO/Issues/2021/03/23/world-economicoutlook-april-2021.

17. The long view how will the global economic order change by $2050 / /$ The world in 2050. - PwC, 2017.

18. Zero Routine Flaring by 2030 [Electronic resource] // The World Bank. - May 10, 2017. — URL: http://www.worldbank.org/en/ programs/zero-routine-flaring-by-2030.

19. Kan E.N. Gumanizacija jekonomicheskogo rosta: sushhnost', napravlenija, mehanizm regulirovanija: avtoref. dis. ... kand. jekon. nauk [Humanization of economic growth: the essence, directions, mechanism of regulation. Ph. D. (Economy) Thesis]. - Saint Petersburg, 2018. 

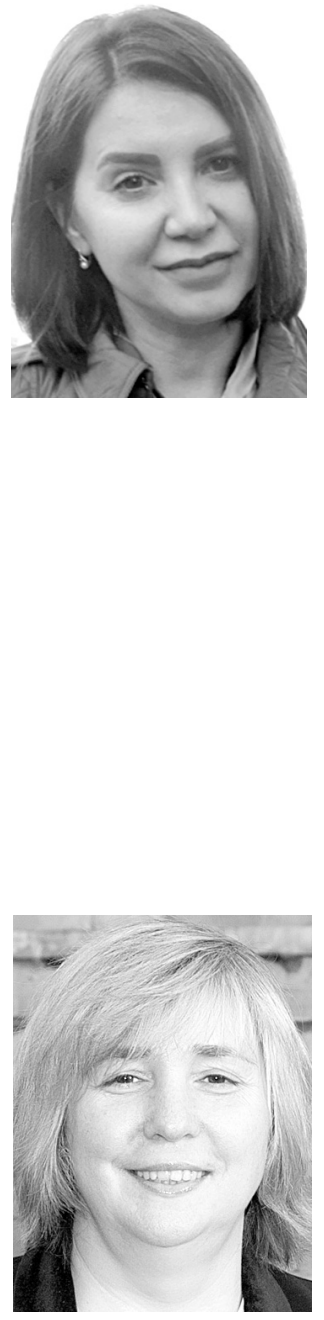

Чубаева Наталья Николаевна - специалист по учебнометодической работе кафедры экономической политики и государственно-частного партнерства Московского государственного института международных отношений (университета) (МГИМО МИД РФ).

Chubaeva Natalia Nickolaevna - Specialist in educational and methodological work of the Department of Economic Policy and Public-Private Partnership, Moscow State Institute of International Relations (University) of the Ministry of Foreign Affairs of the Russian Federation.

119454, г. Москва, пр. Вернадского, 76, ауд. 3034 76 Vernadskogo av., 119454, Moscow, Russia E-mail: Nn1042781@yandex.ru

Попкова Елена Геннадьевна - доктор экономических наук, профессор, ведущий научный сотрудник Центра прикладных исследований кафедры Экономической политики и государственно-частного партнёрства МГИМО МИД РФ, президент АНО «Институт научных коммуникаций» (Москва, Волгоград, Россия). Является руководителем научно-исследовательских проектов, приглашенным редактором в авторитетных международных изданиях, автором более 300 научных публикаций, организатором и активным участником ведущих международных форумов и конференций. Имеет региональные награды в сфере науки и технологии.

Popkova Elena Gennadievna - Doctor of Economic Sciences, Professor, Leading Researcher at the Center for Applied Research of the Department of Economic Policy and Public-Private Partnership of the MGIMO University of the Ministry of Foreign Affairs of the Russian Federation, President of the ANO «Institute of Scientific Communications» (Moscow, Volgograd, Russia). She is the head of research projects, guest editor in reputable international publications, author of more than 300 scientific publications, organizer and active participant of leading international forums and conferences. She has received regional awards in the field of science and technology.

119454, г. Москва, пр. Вернадского, 76, ауд. 3034

76 Vernadskogo av., 119454, Moscow, Russia E-mail: 210471@mail.ru 